\title{
«A la juventud española», don Quijote dreyfussard
}

\author{
Virginia Ramírez MartíN*
}

Ponte en marcha, solo.

Todos los demás solitarios irán a tu lado, aunque no los veas. Cada cual creerá ir solo, pero formaréis batallón sagrado: el batallón de la santa e inacabable cruzada

Unamuno (1961: 100)

En 1898 la opinión pública española centraba su interés en muy diversos asuntos domésticos y, fuera de sus fronteras, de forma significativa, en el caso Dreyfus, un proceso que se vincula en diversas cabeceras con otro acontecimiento judicial que viene a sacudir la conciencia española: la revisión del proceso de Montjuic ${ }^{1}$. No hay apenas periódico que no dedique unas líneas al asunto y son muchos los periodistas y literatos que escriben al respecto del

* Ayuntamiento de Madrid.

1. Más allá de la convergencia que la prensa establece entre ambos procesos judiciales (vid., entre otros muchos ejemplos posibles, «La revisión de un proceso», El País, 18/09/1898, donde se aprovecha la noticia de la consecución por parte de la defensa de la revisión del caso Dreyfus para pedir, a su vez, la revisión del de Montjuich tras enumerar los puntos comunes que existen en uno y otro), es bien cierto que el papel jugado por la opinión pública en lo relativo al proceso de Montjuic guarda importantes similitudes con lo sucedido en torno al caso Dreyfus, tanto es así que Carlos Serrano llega a afirmar, al reflexionar sobre su trascendencia, que «[...] Montjuïc fue una especie de "affaire Dreyfus a la española", que provocó el nacimiento de los "intelectuales" como forjadores de opinión» (vid. Serrano, 1991: 85). 
affaire Dreyfus ${ }^{2}$. En la capital una de las cabeceras que se implica significativamente en el seguimiento del caso es Don Quijote, semanario dirigido en aquel momento por Miguel Sawa ${ }^{3}$.

El semanario Don Quijote, el «diario que se compra pero no se vende» como reza su portada, inicia una campaña singular de adhesión a Zola con don Quijote como hilo conductor. La cabecera madrileña trata de movilizar a sus lectores para conseguir manifestar a Zola el apoyo español a su encendida defensa de la inocencia de Alfred Dreyfus ${ }^{4}$.

Don Quijote se imprime por primera vez en las máquinas de la Imprenta Moderna en 1892 como publicación de formato folio y apenas dos páginas, una de ellas dedicada íntegramente a las caricaturas de Demócrito, seudónimo utilizado por Eduardo Sojo, fundador y primer director del semanario,

2. Una interesante panorámica sobre la repercusión del caso Dreyfus en la sociedad española y su impacto en la prensa de la época se puede encontrar en Jareño López (1981). Téngase en cuenta que, cuando estalla el asunto Dreyfus en Francia, España está inmersa en su propio debate sobre la cuestión judía: el derecho al retorno de los sefarditas. Este es uno de los motivos por los que el asunto Dreyfus apasionó a la opinión pública española. Vid. González García (1991); en el capítulo 2 de la primera parte el autor señala las singulares implicaciones de la «cuestión judía» en España (González García, 1991: 57-63). Este autor ha dedicado gran parte de su investigación a los judíos en la España contemporánea ya desde su tesis doctoral, La cuestión judía y los orígenes del sionismo en la España de la Restauración (1881-1905), leída en la Universidad Complutense de Madrid en 1984, por lo que son muchas sus publicaciones dedicadas a este respecto. Más recientemente han visto la luz dos obras que son de cita indispensable para tratar este asunto: Álvarez Chillida (2002) y Rozenberg (2010).

3. Poca es la bibliografía disponible sobre la figura de Miguel Sawa, si bien tienen bastante interés las semblanzas trazadas por Ángeles Ezama Gil (1994: 77-82) y Sergio Constán (2010). Este último retrata a Miguel Sawa (1866-1910) desde una perspectiva interesante en el prólogo a la edición de su obra póstuma, Historias de locos; lo describe, más allá de su fraternal relación con el «príncipe de la Bohemia», Alejandro Sawa, como admirador de Cervantes y amigo de Manuel Machado, importante figura del periodismo madrileño del fin de siglo y cofundador de la Asociación de la Prensa de Madrid, así como entrañable amigo de escritores, periodistas y bohemios, al tiempo que rescata su faceta de escritor. Miguel Sawa, quizá por su profunda admiración por el universo cervantino, es responsable principal, en colaboración con Pablo Becerra, de la edición de Crónica del centenario del Don Quijote (1905), publicado con ocasión de la celebración del tercer centenario de la publicación de la primera parte de la novela de Cervantes (sobre la conmemoración de esta efeméride, vid. Storm (1998) y «El Ateneo de Madrid y el tercer centenario del Quijote de 1905», en Martínez de Castilla Muñoz (2008: 11-47)).

4. El caso arranca en 1894 con la condena a destierro por alta traición al capitán del Ejército Francés de origen judío Alfred Dreyfus. La familia del condenado comienza a recabar apoyos para defender la inocencia del capitán y solicitar la revisión del caso, al tiempo que tratan de formular acusación contra el comandante Esterhazy, auténtico culpable del delito que, sin embargo, es absuelto en 1898 por el Ministerio de Guerra, que previamente había condenado al capitán. Ese mismo año, coincidiendo con el aumento de partidarios de la inocencia de Dreyfus, Zola publica en L'Aurore «J'Accuse», carta abierta al Presidente de la República y cuya publicación es considerada el auténtico detonante del caso tal y como se conoce, con el estallido de la corriente antisemita en Francia, la movilización de la intelectualidad gala y el desarrollo de la prensa como cuarto poder. La bibliografía sobre el caso en cualquiera de sus aspectos e implicaciones es casi inagotable, lo que da una muestra del calado del acontecimiento. También que desde fechas muy próximas se comenzase a recopilar la información y a publicarla debe dar idea de la importancia que desde el principio se le concedió al caso Dreyfus. 
y una serie de secciones fijas cuyos títulos tratan de evocar el universo quijotesco ${ }^{5}$. Cesa de publicarse definitivamente en 1902. La Hemeroteca de la Biblioteca Nacional de España y la Hemeroteca Municipal del Ayuntamiento de Madrid conservan dos de las colecciones más completas de la cabecera, disponiendo la primera de ellas de la mayor parte de los ejemplares conservados digitalizados y la segunda de la secuencia más extensa por número de ejemplares ${ }^{6}$. El Madrid decimonónico alumbró, sin embargo, otras publicaciones bautizadas con el nombre de personajes cervantinos ${ }^{7}$, si bien es el Don Quijote en la época en la que es dirigido por Miguel Sawa el que se convierte en órgano de expresión de las demandas regeneracionistas. Por sus oficinas pasaron escritores como Maeztu, Pío Baroja, Valle Inclán o Blasco Ibáñez, poetas como Juan Ramón Jiménez, la bohemia capitalina, e insignes periodistas como Luis Bonafoux, también este un destacado dreyfussard y director del diario El Progreso ${ }^{8}$.

De corte satírico y radical, pocos acontecimientos patrios y extranjeros escaparon al peculiar análisis de las páginas de Don Quijote ${ }^{9}$.

Esta singular publicación, del mismo modo que sucede en otras cabeceras madrileñas, mira constantemente a Francia y su atención la atrae de un modo especial Zola y el liderazgo que el literato ejerce sobre la intelectualidad francesa a propósito del caso Dreyfus. Así, no se limita, como es el caso de otros periódicos, a dar noticia de lo que en torno a él está aconteciendo en el país vecino, sino que toma partido por Zola y, de este modo, por la inocencia de Dreyfus para lograr que la sociedad española apoye también la causa.

A la singular iniciativa de Don Quijote pronto se sumarán otros periódicos: desde El Progreso, donde también se recogerán las firmas, hasta la cabecera republicana valenciana El Pueblo, fundada en 1891 y estrechamente vinculada por aquel entonces a Vicente Blasco Ibáñez, a quien unían profundos lazos con el padre del naturalismo ${ }^{10}$. El escritor valenciano relata así cómo obró para

5. Para una explicación detallada de las diversas secciones de la cabecera vid. Varela Olea (2003: 45-47).

6. No puedo dejar de agradecer al personal de la Hemeroteca Municipal de Madrid, y muy especialmente a Susana Ramírez Paredes y Guadalupe Uceta Pérez, la ayuda y facilidades prestadas para la consulta del fondo hemerográfico y obtención de la reproducción que figura en este artículo.

7. Vid. Zabala (1974: 8-20); Armero (2005: 94) y Varela Olea (2003: 41-46).

8. Para abundar sobre la figura de Luis Bonafoux y su activa defensa de Dreyfus y Zola, vid. Jareño López (1983).

9. La historia del semanario Don Quijote en España se estudia con detalle en Rubio Jiménez (1998). Como señala el autor del capítulo, este periódico se convirtió en «una verdadera hermandad de artistas y escritores preocupados por la situación del país y empeñados en modificarla, acogiéndose a la sombra idealista y hasta quimérica del héroe cervantino» (Rubio Jiménez 1998: 300).

10. En abril de 1902, poco antes de la muerte de Zola, Blasco Ibáñez le visita en París. Relata después esta entrevista en Blasco Ibáñez (1902: 187 y ss.). En estas páginas el autor repasa todo aquello que le une al literato francés, confesándose su admirador y deudor intelectual, al tiempo que reseña cómo rememoró con él los sucesos relacionados con el caso Dreyfus y la iniciativa análoga a la de Don Quijote en Madrid que él puso en marcha en Valencia. 
demostrar a Zola su adhesión, de un modo muy parecido al que la cabecera madrileña había decidido hacerlo:

[...] Me encontraba entonces en Valencia y quise hacer saber a Zola que no estaba solo. No sabiendo cómo demostrárselo, a la puerta del diario popular que entonces yo dirigía, hice colocar unas mesas, en las mesas unos pliegos de papel e hice decir que los que en ellos firmasen enviaban un mensaje a Zola. El espectáculo fue tierno e imponente: todo el pueblo pasó a firmar, acudiendo a mi llamamiento. Toscos obreros, con toscos caracteres de letras, ponían su firma. Muchos de ellos no conocían a Zola ni de nombre, otros sólo a través de una novela, los más firmaban porque sabían que Zola sufría. [...] Vino Sorolla, y con Sorolla otros pintores, y llenaron de acuarelas y de pinturas hermosas aquellos pliegos llenos de firmas. Más tarde, los obreros encuadernadores lo encuadernaron en marfil y cantoneras de oro, y los plateros le pusieron letras de plata. Por fin, con más de 60.000 firmas, el álbum fue enviado a París» (Blasco Ibáñez, 1999: 131).

La nota escéptica a la propuesta de Don Quijote la representa Clarín en las páginas de su tribuna, «Palique», en el semanario Madrid Cómico ${ }^{11}$; en ella, y utilizando un tono rayano en la condescendencia al referirse a la «intervención generosa» del «simpático autor del Yo acuso» en el asunto Dreyfus, trata el asunto puesto en marcha por Miguel Sawa ${ }^{12}$. Pues bien, a pesar de que Clarín dice que esta adhesión pública, la de la juventud española a Zola, debiera hacerse, formula varios consejos, pues en su opinión esto no debiera hacerse de cualquier manera, pues «no vaya a resultar que no quede en Medán una vidriera sana» ${ }^{13}$. Asimismo afirma, y esto entronca con la actitud que frente al caso Dreyfus se instala en una parte de la opinión pública española, que:

[...] habría que ponerse bien claro que no se prejuzga la cuestión que divide a los franceses. No se trataba de un voto a favor de Dreyfus, ni de dar por ciertas las acusaciones de carácter general que Zola dirige contra todo es Estado Mayor [...]. El objeto de la juventud española no podía ser erigirse juez de tan difícil litigio, dando sentencia que podría herir legítimos sentimientos nacionales; lo que se querría tendría que ser esto: tributar a Zola homenaje de afecto y admiración por su noble actitud [...] (Botrel, 2003).

11. Para el acercamiento a la cabecera madrileña es indispensable la monografía de Margot Versteeg (2011), y para abundar en la estrecha relación que une a Clarín con ella, vid. Botrel (2003).

12. Clarín, «Palique», Madrid Cómico, Época tercera, n. ${ }^{\circ} 782,12 / 02 / 1898$.

13. Botrel señala que a partir de 1898 , momento en el que se inaugura la tercera época de Madrid Cómico, apartado ya Sinesio Delgado de su dirección, gran parte de su influencia y su carácter «modélico» se han perdido y se convierte en un «semanario para "gente vieja" por oposición a la "gente nueva" y como tal pierde gran parte de su popularidad y autoridad» (Botrel, 2003). Este cambio de rumbo, amén del cambio sustancial habido en su plantilla, podría quizá explicar su posición suspicaz en este asunto, habida cuenta de su línea editorial en otros. 


\section{«A LA JUVENTUD ESPAÑOLA»: EL LLAMAMIENTO DE DON QUIJOTE}

El 28 de enero de 1898 se publica en primera página un artículo suscrito por Miguel Sawa que lleva por título «A la juventud española» ${ }^{14}$. Tras alabar la actitud de Zola en lo que al proceso llevado a cabo contra Alfred Dreyfus se refiere y hacer constar que la opinión pública europea y española están del lado de Zola, añade:

[...] ¿Por qué no hemos de elevarle un mensaje de adhesión y que este mensaje vaya autorizado con las firmas de todos aquellos que somos admiradores del talento de ese hombre excepcional? El mensaje podría decir solamente:

AL MAESTRO EMILIO ZOLA

LA JUVENTUD ESPAÑOLA

Y después una larga lista de firmas, testimonio de que en España hay una juventud inteligente y generosa, simpatizadora de todo lo grande. Nosotros creemos que esta idea debe llevarse a la práctica y desde esta fecha a la del 10 de Febrero próximo, tendremos a disposición del público, en estas oficinas, las listas de adhesión al mensaje que hemos de enviar a Zola.

Los jóvenes de provincias que quieran tomar parte en este homenaje de admiración, podrán hacerlo por medio de cartas o telegramas.

Una vez firmados los pliegos, formaremos con ellos un álbum que enviaremos al maestro.

Y ahora, anunciada la idea, esperemos a ver si la juventud se digna hacerla suya.

Entre el 28 de enero y el 15 de febrero de 1898 se recoge en la mayor parte de los ejemplares publicados la iniciativa en un lugar preferente, pues ocupa las primeras líneas de la primera plana.

En el ejemplar de 18 de febrero de 1898 se informa bajo el título «Mensaje a Zola» de que son ya 2.124 las firmas de adhesión recogidas. Se agradece a los periódicos de Madrid y provincias las frases elogiosas con las que se ha acogido la iniciativa. El 11 de febrero de 1898, apenas cuatro días antes de que se cierre la recogida de firmas de adhesión propuesta por Don Quijote, se publica la caricatura que nos ocupa con el siguiente pie: «Se reciben adhesiones en la redacción de Don Quijote hasta el 15 del actual», al tiempo que en primera página se anuncia, del mismo modo que en muchos de los números anteriores:

a La JUVENTUd eSpañola. homenaje a zola. Se reciben adhesiones hasta el 15 del actual en las oficinas de este periódico y en las de EL PROGRESO, Montera, 51.

14. Don Quijote, 28/01/1898, disponible en la Hemeroteca Digital de la Biblioteca Nacional < http:// hemerotecadigital.bne.es/datos1/numeros/internet/Madrid/Don\%20Quijote\%20\%28Madrid.\%20 1892\%29/1898/189801/18980128/18980128_00000.pdf?\#search=\%22zola\%22>. 


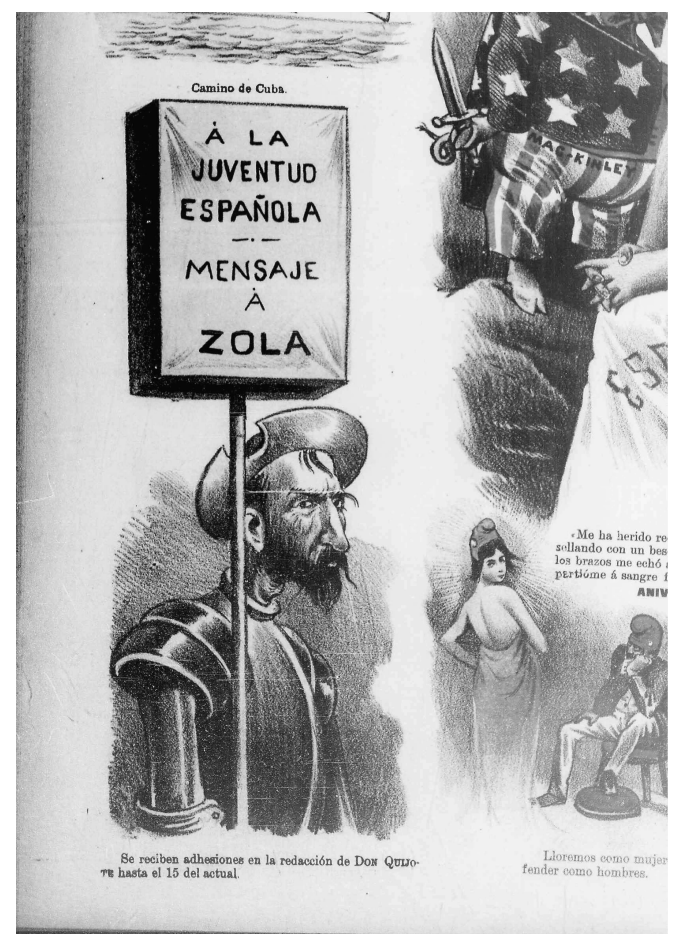

Hemeroteca Municipal de Madrid, Don Quijote, 11 de febrero de 1898.

Un mes después, el 11 de marzo del mismo año, se publica la carta enviada al periódico por Zola en respuesta a la recepción del álbum con las signaturas de todos los interesados:

París, 4 de marzo de 1898

Sr. D. Miguel Sawa, director de Don QUIJOTE.

Mi querido colega: Estoy grandemente emocionado por el Mensaje que usted acaba de enviarme en nombre de la Juventud española, cuyas firmas, con ser tan numerosas, quedarán indeleble y cariñosamente grabadas en mi corazón.

Nada me es tan precioso como la aprobación de esas jóvenes almas entusiastas, prendadas de la verdad y la justicia. Pero no soy yo sino un simple ciudadano, y la brava confianza con que ustedes me favorecen debe ser consagrada a Francia, a Francia entera, que ha sido siempre y volverá a ser de nuevo el país del Derecho y la generosidad.

Gracias, muchas gracias, y soy cordialmente vuestro.

Emilio Zola

La respuesta que dirige Zola al director de Don Quijote es reproducida a su vez por otras muchas cabeceras de provincias, hecho este que da una idea 
aproximada de la difusión que tuvo esta iniciativa en toda la prensa española. Así, entre otros, El Liberal: órgano democrático de la Isla de Menorca, publicado en Mahón, La región extremeña, de Badajoz, El Liberal: diario político y de intereses materiales, publicado en Alicante, o La autonomía: Diario republicano y defensor del partido único, editado en Reus, dan noticia de la carta del literato francés al tiempo que hacen referencia al movimiento de adhesión impulsado por la cabecera madrileña.

El llamamiento a la juventud española de Don Quijote y la caricatura que lo ilustraba alcanzaron, pues, una notable repercusión, también fuera de España. El periodista John Grand Carteret publicó en 1898 esta caricatura en L'Affaire Dreyfus et l'Image: 266 caricatures françaises et étrangères ${ }^{15}$. Es la única ilustración española que recoge en esta selección, a pesar de que se publicaron otras en la prensa española, algunas de ellas en este mismo semanario.

Grand Carteret, en la somera revisión que de la prensa española hace al respecto, explica:

Esta es la imaginería transpirenaica que, a su vez, también se involucra [en la defensa de Dreyfus], a pesar de todas las preocupaciones que monopolizaban la política local, a pesar de Cuba, de las características alegorías de la España mutilada, arruinada, crucificada, empobrecida de hombres y de dinero, a pesar de la predominancia de las imágenes contra los Estados Unidos, de los cerdos vestidos con calzones con los colores de la bandera americana que pueblan todos los periódicos satíricos (Don Quijote, Gedeón, Campana de Gracia, Barcelona cómica...). Añádase que [...] los lápices bosquejan recuerdos de Montjuich, de los condenados por consejos de guerra españoles, y entonces, como Don Quijote, todos consideran que «se debe manifestar, por la gran hermandad latina, que se deben remitir mensajes de adhesión a Zola, defensor del derecho eterno, superior a cualquier razón de Estado» ${ }^{16}$.

La caricatura gozó, pues, de una cierta difusión dentro y fuera de las fronteras españolas. Parece, sin embargo, que el que don Quijote soportase el peso del llamamiento a la juventud española no es accidental: más allá de la denominación del semanario y de que los personajes cervantinos apareciesen con enorme frecuencia en sus caricaturas, esta figura encarna, en el fin de siglo español, una convergencia de ideas y sentires en torno a la obra de Cervantes y a su recepción social (vid. Varela Olea, 2003: 20-32).

15. Asimismo en Don Quijote se da, el 6 de mayo de 1898 en la sección de libros, noticia de la publicación de esta obra con el siguiente texto: «El distinguido redactor de El Fígaro, de París, John Grand-Carteret, ha publicado un curiosísimo libro titulado L'affaire Dreyfus et l'image, en el que se reproducen y se comentan las principales caricaturas que la prensa del mundo ha dedicado a Zola con motivo de su gallarda defensa a favor del condenado de la Isla del Diablo. El libro del Sr. Grand-Carteret, lujosamente editado por la casa Flammarión, se halla de venta en todas las librerías al precio de 3,50 francos»».

16. Grand Carteret (1898: 235); la traducción es mía, si bien se han respetado las cursivas y los entrecomillados del autor. 
El caricaturista recurre a una representación clásica del personaje cervantino, una «iconografía canónica» del caballero ${ }^{17}$ : enjuto, barbudo, de gesto adusto, tocado con el yelmo de Mambrino, y sosteniendo el llamamiento a la juventud española.

La caricatura aparece sin firmar, como es habitual en las ilustraciones que se reservan para la página central del semanario. El único dato que se tiene es el de la impresión de la página ilustrada, que se hace en el establecimiento litográfico de la viuda de M. Bautista, sito en la calle Jesús del Valle, 22, mientras que el resto de la publicación se imprime en la imprenta de Antonio Marzo, ubicada en la calle Apodaca, 18.

La singularidad de esta caricatura, contemplada entre el elenco que muestra la compilación de Grand Carteret, reside en que no presenta a ninguno de los personajes implicados en el asunto ni recurre a otros tópicos tales como, por ejemplo, la encarnación de la justicia o la alegoría de la verdad, sino que presenta a don Quijote tomando partido y como encarnación de los principios sobre los que se fundamenta la defensa abanderada por Zola. La infinita tristeza con la que se ha representado al icono cervantino, en contraposición con otras figuraciones publicadas por la cabecera, parece cuestionar, sin embargo, que los deseos de justicia y verdad hayan calado realmente entre la juventud patria, si bien mantiene la llamada, expectante.

No obstante, el auténtico rasgo diferenciador de esta caricatura radica más bien en que se funden el mitologema de don Quijote con la realidad política y social española, encarnándose España de algún modo en la figura de don Quijote, y ubicándose así en el centro del caso Dreyfus.

El recurso del que se ha hecho uso, pues, tiene que ver con la inserción del tipo que encarna don Quijote en el imaginario social de la España decimonónica, entendiendo que se trata de una construcción ideológica ligada a procesos diversos y heterogéneos de información social. Manuel Pérez Ledesma (1991: 87) reflexiona sobre estas construcciones sociales concluyendo que «Son más bien construcciones mentales [...], y como tales integran en su seno percepciones, actitudes, esperanzas o temores de los grupos sociales que las hacen suyas». Y por tal motivo, traer a don Quijote al primer plano del encendido debate que en torno al caso Dreyfus se está planteando implica que se está buscando conectar con la irracionalidad, la visceralidad si se prefiere, de la defensa primaria y encendida de los valores que encarna el caballero cervantino, más allá de cualquier otra cuestión, pues se presume que todo español que vea a don Quijote abrazar una causa, se adherirá inmediatamente a ella, sin entrar en más cuestiones.

Encarnación Medina defiende también esta idea de interconexión entre los valores representados por don Quijote y la cruzada emprendida por Zola. En la introducción a la monografía que recoge las cartas remitidas desde España

17. Señala José Manuel Lucía (2005: 31) que «muy pronto el Quijote se convirtió en una imagen. En una determinada imagen», hecho este que apuntala la idea de que en el imaginario español finisecular don Quijote no sólo encarna una serie de valores, sino que también tiene una serie de rasgos físicos y una apariencia determinados. 
al escritor francés a propósito del caso Dreyfus la autora afirma que se entabla una suerte de diálogo en el que el mito de don Quijote, y su percepción social en la España del siglo XIX, consigue encarnarse en Zola (vid. Medina Arjona, 1999: 14-15). La ilustración presenta, pues, la fusión de ambos personajes interconectados por el anhelo universal de Justicia.

Sobre que sea la juventud española el destinatario de tal llamamiento es un recurso ya utilizado por este periódico; M. ${ }^{\mathrm{a}}$ Ángeles Varela ofrece otro ejemplo, a saber: la «Arenga de Don Quijote a la gente moza» a propósito del desastre colonial, publicada el 6 de mayo de 1898 y que la autora analiza del siguiente modo:

[...] reproduce un diálogo entre los personajes, exponiendo la rabia del pueblo español, la acusación a los políticos como responsables de la catástrofe, la queja de que el mal es antiguo y, sobre todo, la necesidad de que los jóvenes no se dejen ganar por el desánimo y se enfrenten a la pasividad, intentando recuperar las pocas fuerzas restantes para iniciar la tarea de la regeneración. Don Quijote explica a la juventud cuál ha de ser su actitud: «ella es la que puede remediar, y no a largo plazo, todos los males de la patria». Este es un ejemplo de la solidez del recurso en el momento en que se evidencia la crisis nacional (Varela Olea, 2003: 47).

El mismo Zola, en el artículo que lleva por título «A la juventud» exhorta a los jóvenes diciendo: «¿Quién se levantará para exigir que se haga justicia, sino tú, que no estás en nuestras luchas de intereses y de personas, que no estás aún atada ni comprometida por ningún negocio ambiguo, que puedes hablar alto, con toda pureza y buena fe?» ${ }^{18}$.

Por otra parte, don Quijote es un recurso explotado con reiteración por la prensa de la época y el «quijotismo» una actitud frente a la injusticia, las afrentas o las desigualdades y, en el fondo, una pose muy española al respecto de esas circunstancias ${ }^{19}$. Así titula Luis Bonafoux un artículo que publica en el diario El Progreso: «Nuestro quijotismo».

\section{CONCLUSIONES}

Parece en esta caricatura, a la vista de lo expuesto, que don Quijote enarbola la bandera de la inocencia de Dreyfus pero, sobre todo, reivindica la figura

18. Emilio Zola, «A la juventud», Don Quijote, 11/08/1899.

19. Sirva como ejemplo la recuperación de resultados en la Hemeroteca Digital de la Biblioteca Nacional de España. La búsqueda «quijotismo» arroja, sólo en cabeceras madrileñas y para el intervalo temporal que afecta al caso Dreyfus (no porque los resultados impliquen relación con el caso, sino para fijar un rango de años equivalente), 116 recuperaciones, y de lo más variopintas. El siguiente enlace las recoge: $<$ http://hemerotecadigital.bne.es/results.vm?o=\&w=quijotismo $\& \mathrm{f}=$ text $\& \mathrm{a}=\mathrm{us} \& \mathrm{p}=$ Madrid\&t=\%2Bcreation $\& \mathrm{l}=600 \& \mathrm{l}=700 \& \mathrm{~s}=0 \& \mathrm{y}=1898 \& \mathrm{y}=1905 \&$ lang=es $>$, consultado el 13/06/2013 Tal cantidad de resultados hace pensar en una utilización sistemática del término por parte de la prensa coetánea. 
de Zola, que es el auténtico protagonista de la iniciativa emprendida por el semanario Don Quijote. De este modo el llamamiento a la juventud española recupera una vez más al Quijote romántico y utópico, como demuestra la afirmación de Miguel Sawa: «Siempre juzgaremos a D. Quijote como a un ser utópico y a su escudero Sancho como a la encarnación perfecta de esta mísera humanidad. Pues bien, el héroe de las imaginaciones de Cervantes, ha vuelto de nuevo al mundo, dispuesto, como siempre, a esgrimir sus armas en defensa del débil y del oprimido» ${ }^{20}$.

El proceso de movilización de la intelectualidad española en torno a Zola presenta algunos paralelismos con la movilización acontecida en Francia, si bien diluida por la percepción del caso como ajeno, por una parte, pero especialmente por el desastre del 98 , que ejercerá como auténtico motor de la movilización intelectual española. Al mismo tiempo, el impulsor de la campaña de adhesión a Zola, Miguel Sawa, busca con su iniciativa concitar el interés de toda la opinión pública y, de forma especial, de la juventud española, convirtiendo la respuesta en un movimiento generalizado, no exclusivo de las élites o de los intelectuales, pues la búsqueda de la justicia parece motivo suficiente para la reunión de voluntades muy diversas.

La caricatura publicada es, a imagen del uso intensivo de ésta a lo largo del siglo XIX, arma política (vid. Ramos Santana, 2006), pero de un modo primario es, de igual manera que cualquier imagen, un poderosísimo instrumento de comunicación, capaz de transmitir casi cualquier cosa con apenas unos cuantos trazos, sustituyendo lo escrito e, incluso, llegando a poner en marcha mecanismos humanos de un modo en que lo escrito no puede llegar a aspirar $^{21}$. Este es el punto en el que la imagen objetiva, la representación que se escoge, se funde con el imaginario social al que pertenece, dando una pista de la gran cantidad de planos que su análisis puede llegar a contener. Y esta es precisamente la fuerza de esta caricatura: el universo quijotesco, reflejo del alma española ${ }^{22}$, tiene por objeto la movilización de la juventud en torno a un caso que no afecta a su realidad inmediata, pues está sucediendo en Francia y tiene que ver con el destino de un militar judío. Por ello, el recurso utilizado recurre al poderoso imaginario de las identidades para despertar estos complejos y difusos mecanismos que a veces de otra forma no se podría lograr.

Por fin, es evidente que la representación quijotesca constituye en cierta medida una deformación de la obra cervantina y del auténtico espíritu de su protagonista, si bien muy en sintonía con la recepción decimonónica de am-

20. Miguel Sawa, «A la juventud española», Don Quijote, 28/01/1898.

21. Bernardo Riego (2001: 12) arguye que Ivins ya demostró cómo la tradición de la ilustración gráfica había consolidado un poderosísimo método de comunicación con efectos en el pensamiento y en la civilización occidental, y que estuvo ya ligada a la revolución que introdujo la imprenta.

22. La identificación entre don Quijote y la identidad y el alma españolas le debe mucho a la difusión e interpretación que de la obra cervantina hacen los románticos europeos, quienes apuntalan en buena medida esta percepción de lo español fuera de España. Vid. Romero Tobar (2010). 
bos y, especialmente, con el uso que de ellos hace el regeneracionismo. M. ${ }^{\text {a }}$ Ángeles Varela lo resume así:

[...] la imagen de Don Quijote y su escudero como expresión de quejas y demandas que habrían de aplicarse a la nación, no era algo nuevo, nacido con la crítica regeneracionista. Pero sí fueron los regeneracionistas quienes, por su amor a lo que la tradición tenía de venerable [...] usaron y abusaron tanto de estas figuras que las entronizaron como mitologema salvífico en el que hallar las respuestas a las desdichas (Varela Olea, 2003: 37).

Sin embargo, poco interesa el auténtico espíritu cervantino de la obra y sus personajes, pues la sociedad coetánea está más necesitada de aliento y un hilo que conecte el pasado con las necesidades de su presente. O, utilizando para este propósito las palabras de Unamuno, «¿Qué me importa lo que Cervantes quiso o no quiso poner allí y lo que realmente puso? Lo vivo es lo que yo allí descubro, pusiéralo o no Cervantes, lo que yo allí pongo y sobrepongo y sotopongo» (Unamuno, 1966: vol. VIII, 290).

Queda así patente que don Quijote es, en la crisis del fin de siglo español, un personaje capaz de dar una respuesta a la injusticia y, como un contemporáneo más, tomar partido por la justicia, el derecho y todos los valores que son tenidos por eternos y, cómo no, por Zola y su cruzada a favor de la inocencia del capitán Alfred Dreyfus, convirtiéndose de este modo el caballero de la triste figura en un dreyfussard más.

\section{BIBLIOGRAFÍA CITADA}

Álvarez Chillida, Gonzalo (2002). El antisemitismo en España. La imagen del judio (18122002). Madrid: Marcial Pons.

Armero, Álvaro (2005). Visiones del Quijote. Sevilla: Renacimiento.

Blasco Ibáñez, Vicente (1902). «Una visita a Zola», en Paul Alexis, Luis Bonafoux y Vicente Blasco Ibáñez, Emilio Zola: su vida y sus obras. Valencia: Sempere y Cia.

Blasco Ibáñez, Vicente (1999). ¡Diputado Blasco Ibáñez!: memorias parlamentarias. Madrid: HMR.

Botrel, Jean-François (2003). «Clarín y el Madrid cómico: historia de una colaboración (1883-1901)». Alicante: Biblioteca Virtual Miguel de Cervantes, disponible en $<\mathrm{http}: /$ www.cervantesvirtual.com/obra/clarn-y-el-madrid-cmico---historia-de-una-colaboracin-18831901-0/>.

Ezama Gil, Ángeles (1994). «Cuentos de locos y literatura fantástica. Aproximación a su historia entre 1868 y 1910», Anthropos, pp. 77-82.

Grand Carteret, John (1898). L'Affaire Dreyfus et l'image: 266 caricatures françaises et étrangères. París: Flammarion.

González García, Isidro (1991). El retorno de los judios. Madrid: Nerea.

Jareño López, Jesús (1981). El affaire Dreyfus en España (1894-1906). Murcia: Godoy. Jareño López, Jesús (1983). «Un dreyfusista enragé, el español Luis Bonafoux», en VV.AA., Filosofía, sociedad e incomunicación. Homenaje a Antonio García Martínez. Murcia: Universidad de Murcia, pp. 186-197. 
Lucía Megías, José Manuel (2005). «Don Quijote de La Mancha: del libro al mito», en VV.AA., En torno al Quijote: Adaptaciones, imitaciones, imágenes y música en la Biblioteca. Madrid: Biblioteca Histórica Municipal de Madrid-Ayuntamiento de Madrid, pp. 27-55.

Martínez de Castilla Muñoz, Nuria (ed.) (2008). Don Quijote en el Ateneo de Madrid. Madrid: Sociedad Estatal Quinto Centenario, pp. 11-47.

Pérez Ledesma, Manuel (1991). «Ricos y pobres; pueblo y oligarquía; explotadores y explotados. Las imágenes dicotómicas en el siglo XIX español», Revista del Centro de Estudios Constitucionales. 10, pp. 59-88.

Ramos Santana, Alberto (2006). «Formación y manipulación de la opinión: la caricatura», en Marieta Campos Casenave (ed.), Redes y espacios de opinión pública. XII encuentros de la Ilustración al Romanticismo, 1750-1850. Cádiz, América y Europa ante la Modernidad. Cádiz: Servicio de Publicaciones de la Universidad de Cádiz, pp. 567-582.

Riego, Bernardo (2001). La construcción social a través de la fotografía y el grabado informativo en el España del siglo XIX. Santander: Servicio de Publicaciones de la Universidad de Cantabria.

Romero Tobar, Leonardo (2010). «Siglo XIX: El Quijote de románticos y realistas», en VV.AA., El Quijote: biografia de un libro (1605-2005). Madrid: Biblioteca Nacional, pp. 119-136.

Rozenberg, Danielle (2010). La España contemporánea y la cuestión judía. Madrid: Casa Sefarad-Israel y Marcial Pons.

Rubio Jiménez, Jesús (1998). «Don Quijote (1892-1903): prensa radical, literatura e imagen», en Leonardo Romero Tobar (ed.), El camino hacia el 98 (Los escritores de la Restauración y la crisis del fin de siglo). Madrid: Visor Libros y Fundación Duques de Soria, pp. 297-315.

Sawa, Miguel (2010). Historias de locos, Sergio Constán (ed.). Sevilla: Renacimiento.

Serrano, Carlos (1991). «Los "intelectuales” en 1900: ¿ensayo general?», en Serge Salaün y Carlos Serrano (eds.), 1900 en España. Madrid: Espasa Universidad, pp. 85-106.

Soler, M. a de los Ángeles (1961). Pensamiento español contemporáneo: antología. Madrid: Taurus.

Storm, Eric (1998). «El Tercer Centenario del Don Quijote en 1905 y el nacionalismo español», Hispania. Revista Española de Historia. 199, pp. 625-654.

Unamuno, Miguel de (1966). «Del sentimiento trágico de la vida», en Obras completas. Madrid: Escelicer.

Varela Olea, M. Ángeles (2003). Don Quijote, mitologema nacional. Madrid: Centro de Estudios Cervantinos.

Versteeg, Margot (2011). Jornaleros de la pluma: la (re)definición del papel del escritor-periodista en la revista Madrid Cómico. Madrid-Frankfurt am Main: Iberoamericana-Vervuert.

Zabala, Iris M. (1974). Fin de siglo, Modernismo, 98 y bohemia. Madrid: Edicusa.

Recibido: 22 de julio de 2013

Aceptado: 9 de diciembre de 2013

\section{Resumen}

En 1898 la prensa española ocupa parte de sus páginas con un asunto de relevancia internacional: el caso Dreyfus. Entre la cobertura prestada al asunto por todas las cabeceras destaca la hecha por el semanario satírico madrileño Don Quijote; tanto es así que desde su dirección se llega a impulsar un movimiento de adhesión a Zola que tiene por fin la 
recogida de firmas que hagan saber al literato francés que España está de su lado. Dicha iniciativa se completa con un llamamiento a la juventud española que se ilustra con una caricatura quijotesca. El personaje cervantino encarna la defensa de la justicia y logra difundir en la crisis del fin de siglo español la imagen del hidalgo caballero que se había forjado en el imaginario español, como un cruzado luchando a favor de una noble causa, convirtiendo así a Don Quijote en un dreyfussard más.

Palabras clave: prensa satírica madrileña; Don Quijote; Miguel Sawa; Emile Zola; Alfred Dreyfus; caricatura.

Title: To the Spanish Young People: Don Quixote Dreyfussard

\begin{abstract}
In 1898, Spanish press take up part of its pages with a relevant international issue: the Dreyfus affair. The case was widely covered by Spanish newspapers, in special by Don Quijote, a Madrilenian satiric press, whose Director promoted a campaign in favour of Zola collecting signatures in order to the French litterateur was aware that Spain was close to him. This initiative is completed with a call to Spanish young people who is illustrated with a quixotic caricature. Cervantine character personifies the idea of justice getting to transmit during the Spanish crisis at the end of the nineteenth century the image of the nobleman forged by Spanish stereotypical, like a crusader fighting for a noble cause, thus turning Don Quixote into another dreyfussard.
\end{abstract}

Key Words: Spanish satiric press; Don Quixote; Miguel Sawa; Emile Zola; Alfred Dreyfus; Drawing. 